\title{
Mating alters gene expression patterns in Drosophila melanogaster male heads
}

Lisa L Ellis ${ }^{1,2}$, Ginger E Carney ${ }^{1 *}$

\begin{abstract}
Background: Behavior is a complex process resulting from the integration of genetic and environmental information. Drosophila melanogaster rely on multiple sensory modalities for reproductive success, and mating causes physiological changes in both sexes that affect reproductive output or behavior. Some of these effects are likely mediated by changes in gene expression. Courtship and mating alter female transcript profiles, but it is not known how mating affects male gene expression.

Results: We used Drosophila genome arrays to identify changes in gene expression profiles that occur in mated male heads. Forty-seven genes differed between mated and control heads 2 hrs post mating. Many matingresponsive genes are highly expressed in non-neural head tissues, including an adipose tissue called the fat body. One fat body-enriched gene, female-specific independent of transformer (fit), is a downstream target of the somatic sex-determination hierarchy, a genetic pathway that regulates Drosophila reproductive behaviors as well as expression of some fat-expressed genes; three other mating-responsive loci are also downstream components of this pathway. Another mating-responsive gene expressed in fat, Juvenile hormone esterase (Jhe), is necessary for robust male courtship behavior and mating success.

Conclusions: Our study demonstrates that mating causes changes in male head gene expression profiles and supports an increasing body of work implicating adipose signaling in behavior modulation. Since several matinginduced genes are sex-determination hierarchy target genes, additional mating-responsive loci may be downstream components of this pathway as well.
\end{abstract}

\section{Background}

Behavior involves the perception and processing of sensory information into a signaling cascade that mediates physiological and motor outputs. This complex process is influenced by an organism's environment, genetic make-up and nervous system function. Social interactions influence an organism's behavior [1-5], and these behavioral changes are associated with alterations in morphology [6-9] and gene expression [6,10-17]. However, the mechanisms mediating the changes are unclear. As we work to understand responses to behavior at the transcript level, we can clarify the regulatory and intracellular processes governing nervous system function and behavior.

\footnotetext{
* Correspondence: gcarney@mail.bio.tamu.edu

'Department of Biology, Texas A\&M University, College Station, TX USA 77843-3258

Full list of author information is available at the end of the article
}

Therefore, we are studying reproductive behaviors in the genetically tractable Drosophila melanogaster, which exhibit stereotypical mating behaviors [reviewed in $[18,19]]$ regulated by genetics [reviewed in $[20,21]]$ and social interactions [[1,22,23]; reviewed in $[19,24,25]]$. The sex-determination gene hierarchy is the major regulator of Drosophila reproduction [reviewed in [26,27]]. Components of this pathway affect sexually dimorphic development, including the neural circuitries necessary for sex-specific courtship behaviors [28-32]. However, the behavioral functions of only a few of the downstream target genes of the hierarchy are known [33-43].

Although the potential for performing courtship behavior is under genetic control, experience with other individuals alters behavior, particularly in the context of courtship learning $[19,24,25]$. During courtship and mating, the male is inundated with sensory information that must be interpreted so that the appropriate signals are sent throughout the body for a successful mating. 
Therefore, it is reasonable to expect that a more experienced male would be better at performing some aspect of courtship to improve his mating success. In support of this idea, Drosophila males experienced at courting females initiate courtship toward novel, receptive females more quickly than do inexperienced males $[44,45]$. In a natural setting where many flies are competing for mates, rapid courtship initiation may give an experienced male a competitive advantage that increases his mating success. Simply observing courtship and mating behavior of other flies is not sufficient to decrease the male's own mating latency, indicating that this learning behavior requires active participation [45]. It is possible that changes in courting and mated male gene expression underlie this decreased courtship latency in subsequent interactions.

By combining behavioral assays with microarray technology, it is possible to assess behaviorally-responsive gene expression changes on a genome-wide scale $[12,22,46-51]$ to find loci regulating or regulated by behavior, including sex-determination hierarchy target genes. Prior work in our lab demonstrated that males rapidly alter gene expression at the whole-animal level during courtship [12,22]. Next, we focused on changes occurring in the male head as a result of mating since these changes likely affect function of the nervous system and other reproductively important tissues to promote reproductive success. Our study demonstrates that courtship culminating in mating affects gene expression patterns in male heads and that many of the gene products are expressed in non-neural adipose tissue that may play an important modulatory role in neural function and behavior.

\section{Results and Discussion}

\section{Mating causes expression changes in male heads}

Gene expression levels change rapidly as males court females [12,22]. To determine the effects of courtship culminating in mating on male gene expression, we compared transcriptional profiles of males that mated with a female to those that were not presented with a female (control). Labeled samples from control and treatment groups were hybridized to Drosophila Genome 2.0 Arrays (Affymetrix, Santa Clara, CA, USA), which are based on the Flybase 3.1 annotation, targeting nearly 18,500 transcripts.

In the current study we focused on head expression, rather than whole body expression [12,22], to identify gene expression changes in the nervous system and other tissues within the head (such as sensory systems and fat body) that likely modulate reproduction. We isolated male heads (rather than dissecting out the brains) since accumulating evidence from our lab [[12,22]; L.L. Ellis and G.E. Carney, unpublished results] as well as from other published studies [[37,39,40,43]; reviewed in [52]] indicates that head tissues, such as the fat body surrounding the brain (Fig. 1), likely also have important modulatory functions in behavior. To have the potential to identify gene expression changes in these tissues as well, we elected to assay the entire male head for alterations in gene expression patterns in response to mating.

We used five algorithms to extract expression values from each array and performed paired $t$-test comparisons between the expression values derived from mated male head arrays and control male head arrays. Using this strategy we identified 47 mating-responsive genes (See Methods). Two hours after mating with a female, males significantly up regulated 25 genes (Table 1) and down regulated 22 genes (Table 2). Such changes are not likely to be activity-dependent since control males had locomotor levels similar to males that courted females (two-tailed $t$-test, $\mathrm{p}>0.05$ ).

\section{Verification of microarray results by independent qPCR}

To confirm the microarray results, we performed qPCR analysis on independently collected mated and control male head RNA samples. We tested a subset of genes whose expression levels changed significantly in mated male heads compared to control male heads. Eight out of 10 up-regulated genes and 2 out of 3 down-regulated genes had the expected directional change (Table 3). We did not verify up regulation of CG4825 and fit or down regulation of CG8112 by qPCR. However, increased fit expression in the fat body lining the brain was confirmed by in situ hybridization (see below).

\section{Expression of candidate genes is not restricted to the brain}

We hypothesized that examining gene expression in head tissue instead of whole bodies would uncover genes that function in reproduction by regulating nervous system signaling. This could be via direct effects on neural gene expression or by effects on other tissues in the head that receive or respond to courtship and mating signals. We found that expression of many mating-responsive genes is enriched in the head but not the brain (Table 4) [53], indicating expression occurs outside of the brain. While some of the genes are expressed in the eye, others appear enriched in tissues other than the brain and eye.

One possibility is that they are expressed in an adipose tissue called the fat body that lines the head cavity surrounding the brain (Fig. 1a-d) and is implicated in courtship behavior modulation [[37,39,40,43]; reviewed in [52]]. Data showing that mating-responsive genes enriched in the head are also enriched in the adult fat body (Table 4) [53] support this hypothesis. In situ hybridization confirmed that several mating-responsive loci 


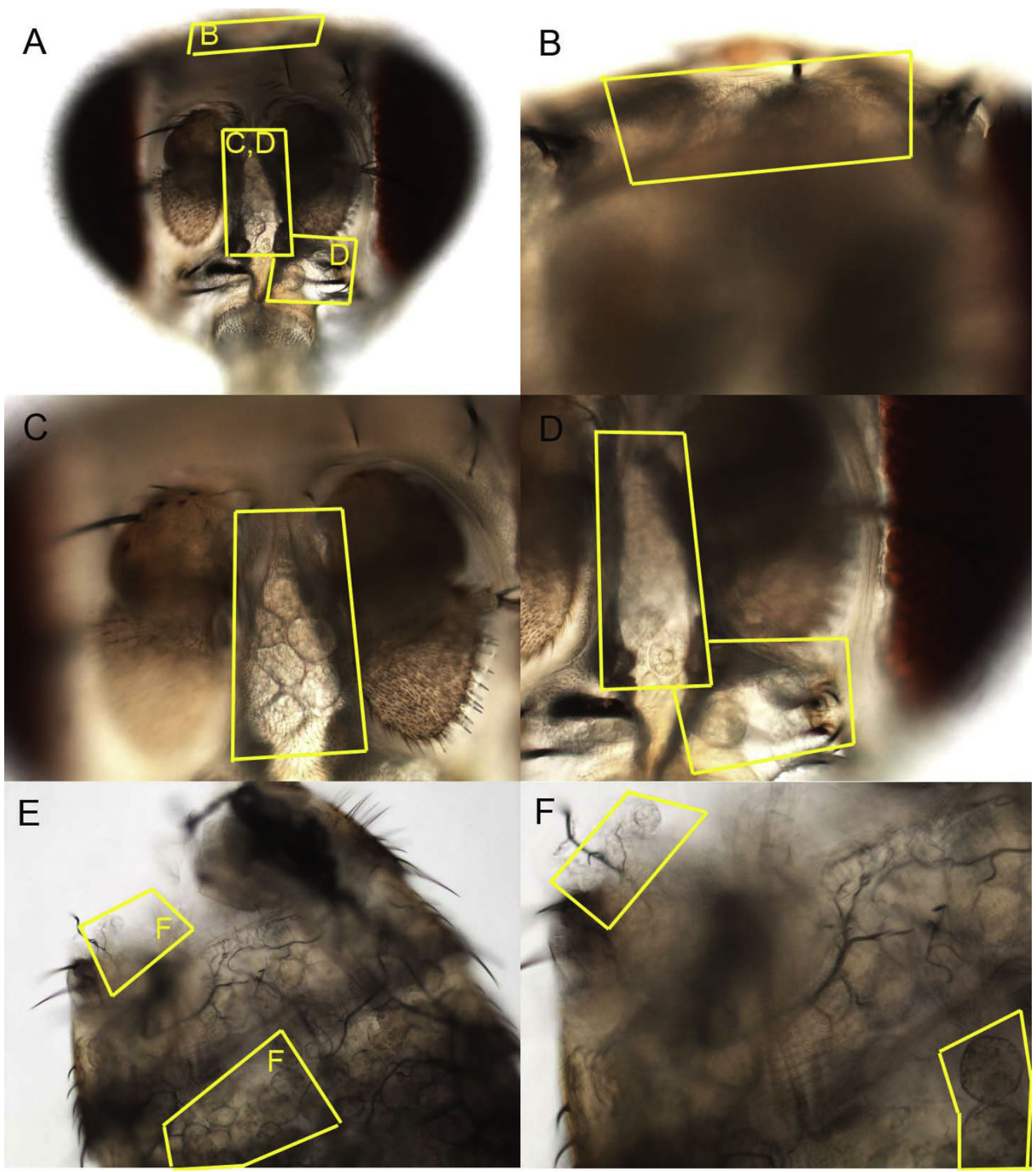

Figure 1 Fat body tissue in the adult male. Low magnification image (10x) from the front of an adult male head (A) or dorsal abdominal cuticle (E). Boxed areas indicate adipose tissue magnified at 20x in 3 areas of the head (B-D) and 2 areas along the abdominal cuticle (F).

(CG13360, bubblegum (bgm), Prx2540-2, CG8449 and CG4825) are expressed in male fat body tissue (Fig. 2).

FlyAtlas data indicate that the fat-expressed genes CG13360, bgm, and Prx2540-2 are expressed at very low levels in brains, while CG8449 and CG4825 are expressed at low to moderate levels in the brain [53]. By in situ we did not detect brain expression of these five transcripts (Fig. 2 and data not shown), although we cannot rule out the possibility that low levels of message are present.

To test the hypothesis that mating-induced changes in gene expression occur in the fat body, we compared fit expression in the heads of mated and control heads. fit expression increased in the adipose tissue surrounding the male brain after courtship culminating in mating (Fig. 3). 
Table 1 Candidate genes up regulated 2 hrs after mating

\begin{tabular}{|c|c|c|c|c|}
\hline $\begin{array}{c}\text { Gene } \\
\text { identifier }\end{array}$ & Gene name & $\begin{array}{l}\text { Avg. fold } \\
\text { change }\end{array}$ & GO Molecular function & GO Biological process \\
\hline CG2163 & polyA-binding protein II (Pabp2) & 1.4 & Poly(A) binding & mRNA polyadenylation \\
\hline CG4288 & & 1.28 & $\begin{array}{l}\text { High affinity inorganic phosphate: sodium } \\
\text { symporter activity }\end{array}$ & Transport \\
\hline CG4501 & bubblegum (bgm) & 1.38 & Long-chain-fatty acid-CoA ligase activity & $\begin{array}{l}\text { Long-chain fatty acid metabolic } \\
\text { process }\end{array}$ \\
\hline CG4825 & Phosphatidyl-serine synthase & 1.22 & $\begin{array}{l}\text { CDP-diacylglycerol-serine O- } \\
\text { phosphatidyltrans-ferase activity }\end{array}$ & $\begin{array}{l}\text { Phosphatidyl-serine } \\
\text { biosynthetic process }\end{array}$ \\
\hline CG5527 & & 1.23 & Endothelin-converting enzyme activity & Proteolysis \\
\hline CG5618 & & 1.14 & Dipeptidyl-peptidase III activity & Proteolysis \\
\hline CG6188 & & 1.64 & Glycine N-methyltransferase activity & Unknown \\
\hline CG6342 & Iron regulatory protein $1 B($ Irp-1B) & 1.26 & Iron ion binding & $\begin{array}{l}\text { Regulation of translational } \\
\text { initiation by iron }\end{array}$ \\
\hline CG8425 & Juvenile hormone esterase (Jhe) & 1.86 & Juvenile-hormone esterase activity & $\begin{array}{l}\text { Juvenile hormone catabolic } \\
\text { process }\end{array}$ \\
\hline CG8449 & & 1.28 & Rab GTPase activator activity & $\begin{array}{l}\text { Regulation of Rab GTPase } \\
\text { activity }\end{array}$ \\
\hline CG9989 & & 1.52 & Endonuclease activity & Unknown \\
\hline CG11765 & Peroxiredoxin 2540 (Prx2540-2) & 1.2 & Antioxidant activity & Unknown \\
\hline CG12116 & & 1.22 & Sepiapterin reductase activity & Metabolic process \\
\hline CG13360 & & 1.28 & Unknown & Unknown \\
\hline CG13607 & & 1.23 & Unknown & Unknown \\
\hline CG13965 & & 1.35 & Unknown & Unknown \\
\hline CG16772 & & 1.5 & Unknown & Unknown \\
\hline CG16901 & squid (sqd) & 1.25 & mRNA binding & Oocyte axis determination \\
\hline CG17364 & & 1.67 & GTP binding & Microtubule-based process \\
\hline CG17820 & $\begin{array}{l}\text { female-specific independent of transformer } \\
\text { (fit) }\end{array}$ & 1.4 & Unknown & Unknown \\
\hline CG18262 & & 1.3 & Zinc ion binding & Unknown \\
\hline CG30026 & & 1.42 & Unknown & Unknown \\
\hline CG30095 & & 1.86 & Oxidoreductase activity & Metabolic process \\
\hline CG30084 & $\begin{array}{l}Z \text { band alternatively spliced PDZ-motif } \\
\text { protein } 52 \text { (Zasp52) }\end{array}$ & 1.38 & Protein binding & Unknown \\
\hline CG33486 & asparagine synthetase & 1.28 & $\begin{array}{c}\text { Asparagine synthetase (glutamine- } \\
\text { hydrolyzing) activity }\end{array}$ & $\begin{array}{l}\text { Asparagine biosynthetic } \\
\text { process }\end{array}$ \\
\hline
\end{tabular}

Twenty-five genes are significantly $(p<0.001)$ up regulated in male heads 2 hrs after mating when compared to control male heads.

Juvenile hormone esterases are important for male reproductive behaviors

We hypothesized that if a gene is up regulated after mating, that gene likely affects some aspect of reproductive behavior. Therefore, we assayed the percentage of time a male spent courting a female, known as the courtship index $(\mathrm{CI})$, of candidate mating-responsive gene mutants. A Jhe P-element insertion, Jhe e01859, resulted in significantly reduced CI values in homozygous mutant males compared to heterozygous or wild-type controls (Fig. 4). Heterozygous males showed similar courtship activity compared to wild-type males, ruling out heterozygous effects on $\mathrm{CI}$ levels. Though Jhe males court females less vigorously, they perform standard courtship steps, eventually culminating in copulation.
In addition to The there are three other candidate juvenile hormone esterase genes in the Drosophila genome [54]. One of the genes, cricklet (clt), also had an available P-element insertion, so we tested $c l t^{B G 01317}$ mutants to see if they had a similar phenotype to Jhe mutants. We found that clt mutants also have decreased CIs relative to controls (Fig. 4). There is also a strong genetic interaction between Jhe and clt. Transheterozygous mutant males had significantly reduced courtship compared to controls (Fig. 4).

We predicted that mating-responsive loci would function to prime the male for subsequent mating encounters by regulating courtship or mating latency and duration. Therefore, we predicted that decreasing Jhe, which was up regulated in mated male heads, would increase courtship or mating latency. To test this 
Table 2 Candidate genes down regulated 2 hrs after mating

\begin{tabular}{|c|c|c|c|c|}
\hline $\begin{array}{c}\text { Gene } \\
\text { identifier }\end{array}$ & Gene name & $\begin{array}{l}\text { Avg. fold } \\
\text { change }\end{array}$ & GO Molecular function & GO Biological process \\
\hline CG1897 & Drop (Dr) & -1.5 & DNA binding & Central nervous system development \\
\hline CG2505 & $\alpha$-Esterase-2 $(\alpha$-Est2) & -1.3 & Carboxylesterase activity & Unknown \\
\hline CG3200 & $\begin{array}{l}\text { Rhythmically expressed gene } 2 \\
\text { (Reg-2) }\end{array}$ & -1.27 & Phosphoglycolate phosphatase activity & Metabolic process \\
\hline CG3926 & $\begin{array}{l}\text { Serine pyruvate aminotrans- } \\
\text { ferase (Spat) }\end{array}$ & -1.34 & Serine-pyruvate transamine activity & Glyoxylate catabolic process \\
\hline CG4105 & Cytochrome P450-4e3 (Сур4e3) & -1.3 & Electron carrier activity & Unknown \\
\hline CG5840 & & -1.34 & Pyrroline-5-carboxylate reductase activity & Proline biosynthetic process \\
\hline CG6806 & Larval serum protein 2 (Lsp2) & -1.28 & Nutrient reservoir activity & Transport \\
\hline CG7224 & & -1.16 & Unknown & Unknown \\
\hline CG7390 & $\begin{array}{c}\text { senescence marker protein-30 } \\
(\text { (smp-30) }\end{array}$ & -1.36 & Unknown & Unknown \\
\hline CG8112 & & -1.42 & Sterol O-acyltransferase activity & Unknown \\
\hline CG8846 & Thor & -1.26 & Eukaryotic initation factor $4 \mathrm{E}$ binding & Immune response \\
\hline CG9416 & & -1.25 & Sequence-specific DNA binding & Regulation of transcription \\
\hline CG9733 & & -1.6 & Trypsin activity & Proteolysis \\
\hline CG11909 & target of brain insulin (tobi) & -1.42 & $\alpha$-glucosidase activity & Carbohydrate metabolic process \\
\hline CG11919 & & -1.36 & ATP binding & $\begin{array}{c}\text { Peroxisome organization and } \\
\text { biogenesis }\end{array}$ \\
\hline CG16898 & & -1.68 & Unknown & Unknown \\
\hline CG18003 & & -1.36 & Glycolate oxidase activity & Metabolic process \\
\hline CG30489 & Cyp12d1-p & -1.3 & Electron carrier activity & Unknown \\
\hline CG31075 & & -1.26 & Aldehyde dehydrogenase (NAD) activity & Pyruvate metabolic process \\
\hline CG31628 & adenosine 3 (ade3) & -1.28 & $\begin{array}{l}\text { Phosphoribo-sylamine-glycine ligase } \\
\text { activity }\end{array}$ & Purine base biosynthetic process \\
\hline CG31689 & & -1.25 & ATPase activity & Unknown \\
\hline CG33462 & & -4.08 & Trypsin activity & Proteolysis \\
\hline
\end{tabular}

Average fold changes, molecular functions and biological processes are shown for 22 genes that are significantly $(p<0.001)$ down regulated in male heads 2 hrs after mating.

hypothesis we examined the courtship and mating kinetics of mutants for Jhe and the related esterase clt. Courtship latency (time to initiation of courtship) did not differ among mutants and controls. Though Jhe and clt males mated with females, they had a significant $(\mathrm{p}<$ 0.05) increase in mating latency (Fig. 5) (ANOVA, genotype $\mathrm{p}<0.05$, trial $\mathrm{p}>0.05$ ), while mating duration was unaffected. The increased mating latency was not dependent on the mating trial $\left(1^{\text {st }}, 2^{\text {nd }}\right.$ or $\left.3^{\text {rd }}\right)$. However, as we increased the number of mating attempts, the mating success (as measured by the act of copulation) of Jhe and clt mutant males was significantly reduced

Table 3 Confirmation of microarray results by qPCR

\begin{tabular}{|c|c|c|c|c|c|}
\hline $\begin{array}{c}\text { Gene } \\
\text { identifier }\end{array}$ & $\begin{array}{c}\text { Gene } \\
\text { symbol }\end{array}$ & $\begin{array}{l}\text { Microarray } \\
\text { Fold change }\end{array}$ & $\begin{array}{l}\text { qPCR Relative fold } \\
\text { change } \pm \text { SEM }\end{array}$ & $\begin{array}{l}\text { Avg. relative expression level in } \\
\text { control male heads } \pm \text { SEM }\end{array}$ & $\begin{array}{l}\text { Avg. relative expression level in } \\
\text { mated male heads } \pm \text { SEM }\end{array}$ \\
\hline CG5618 & & 1.14 & $2.02 \pm 0.49^{*}$ & $0.36 \pm 0.09$ & $0.74 \pm 0.18$ \\
\hline CG6188 & & 1.64 & $1.94 \pm 0.26^{*}$ & $2.25 \pm 0.42$ & $4.38 \pm 0.58$ \\
\hline CG8449 & & 1.28 & $1.35 \pm 0.15^{*}$ & $1.24 \pm 0.26$ & $1.68 \pm 0.18$ \\
\hline CG16772 & & 1.5 & $4.07 \pm 1.55$ & $6.86 \pm 1.72$ & $27.94 \pm 10.61$ \\
\hline CG30026 & & 1.42 & $2.23 \pm 0.35^{*}$ & $4.36 \pm 0.84$ & $9.74 \pm 1.53$ \\
\hline CG4501 & bgm & 1.38 & $4.47 \pm 1.11^{*}$ & $1.42 \pm 0.31$ & $6.37 \pm 1.57$ \\
\hline CG6342 & $\operatorname{Irp}-1 B$ & 1.26 & $1.42 \pm 0.12$ & $1.09 \pm 0.18$ & $1.55 \pm 0.13$ \\
\hline CG11765 & $\begin{array}{c}\operatorname{Pr} \times 2540- \\
2\end{array}$ & 1.2 & $1.23 \pm 0.12^{*}$ & $0.47 \pm 0.08$ & $0.58 \pm 0.06$ \\
\hline CG2505 & $\alpha$ Est2 & -1.3 & $-1.26 \pm 0.15$ & $2.84 \pm 0.59$ & $2.25 \pm 0.42$ \\
\hline CG7390 & smp-30 & -1.36 & $-1.69 \pm 0.16^{*}$ & $1.28 \pm 0.45$ & $0.77 \pm 0.2$ \\
\hline
\end{tabular}

* Indicates a significant $(p<0.05)$ difference between the average relative expression level in control male heads and mated male heads. SEM $=$ Standard error of the mean. 
Table 4 Candidate genes are enriched in head tissue other than the brain, including adult adipose tissue

\begin{tabular}{llllll}
\hline & Total no. of genes & Head & Brain & Eye & Fat body \\
\hline Up regulated & 25 & 18 & 4 & 9 & 16 \\
Down regulated & 22 & 20 & 2 & 12 & 18 \\
\hline
\end{tabular}

Data was compiled from FlyAtlas [53].

(Fig. 6) (Binary Logistic Regression, genotype $\mathrm{p}<0.01$, trial $\mathrm{p}<0.0001$, interaction $\mathrm{p}<0.0001)$ compared to heterozygous controls. Since we ruled out a heterozygous effect on CI values we did not test for heterozygous effects on mating latency or mating success. Females mated to Jhe or clt mutant males laid equivalent numbers of eggs regardless of the mating trial and day of egg laying (ANOVA, genotype $\mathrm{p}>0.05$, trial $\mathrm{p}>$ 0.05 , day $\mathrm{p}>0.05)$, and neither Jhe nor clt mutant females had detectable fertility defects.

\section{Conclusions}

\section{Changes in gene expression upon mating}

The complex reproductive behaviors exhibited by Drosophila require the interaction between genetics and environment. Courtship is an innate and stereotypical process under control of the somatic sex-determination hierarchy and is influenced by social interactions. Courtship and mating elicit gene expression changes in females [49,55-57], and courtship affects transcript profiles in males [12,22]. The female post-mating effects occur rapidly (within minutes) or can be detected several hours after mating [49,55-57]. Within 5 min of courtship, whole-male gene expression profiles also change rapidly $[12,22]$. In this study we expanded on our earlier studies in whole males to show that courtship culminating in mating causes changes in gene expression in the male head as well. Expression levels likely change rapidly in response to sensory cues received during courtship, while the physiological changes from mating [58] may mediate long-term expression level changes in the nervous system or elsewhere in the fly that can feed back to the nervous system.

The expression profile of a 5 min courting male differs from that of a $2 \mathrm{hr}$ post-mating male. This is not surprising since we expected that the process of mating would have major effects on male physiology that would

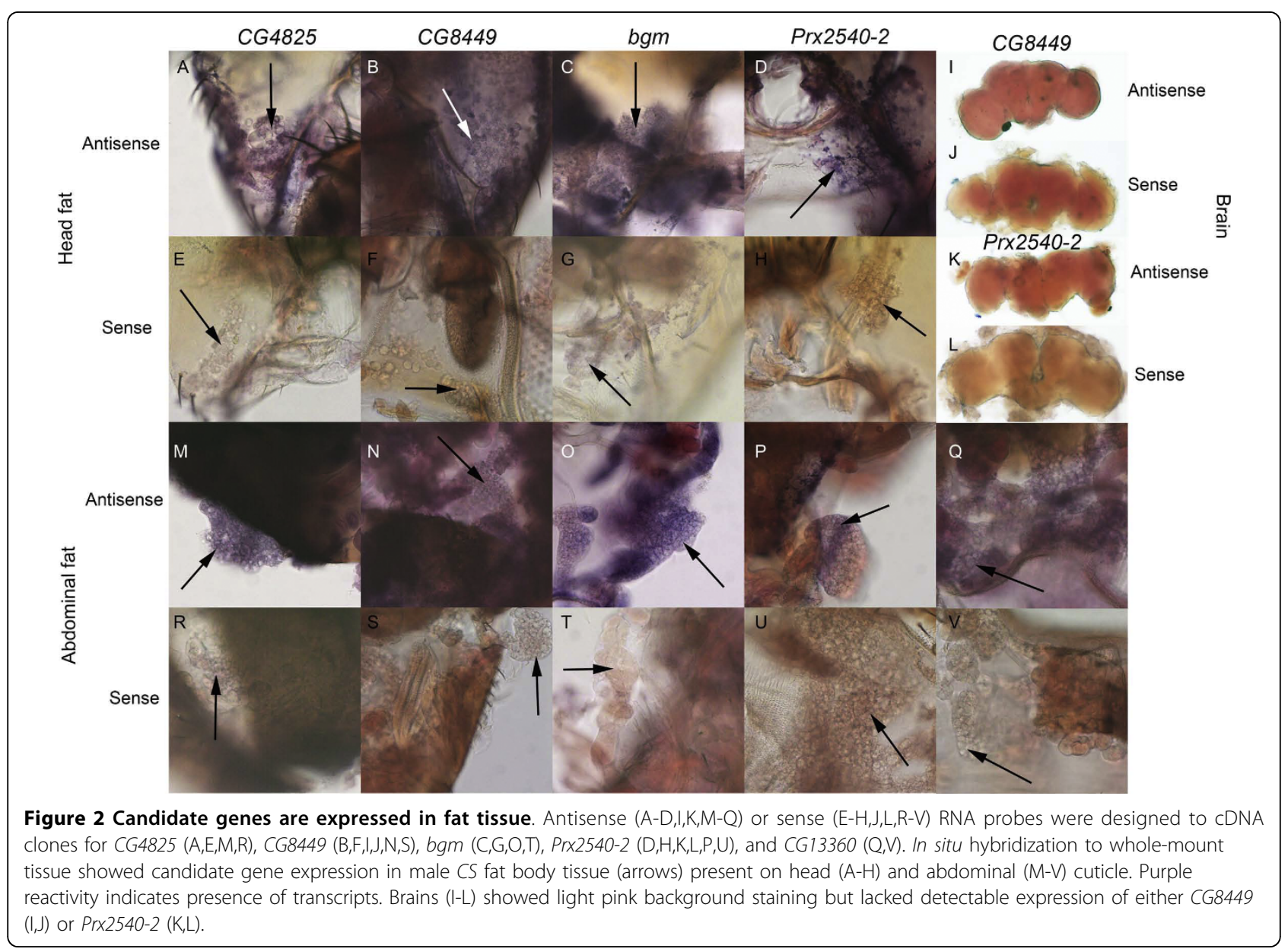




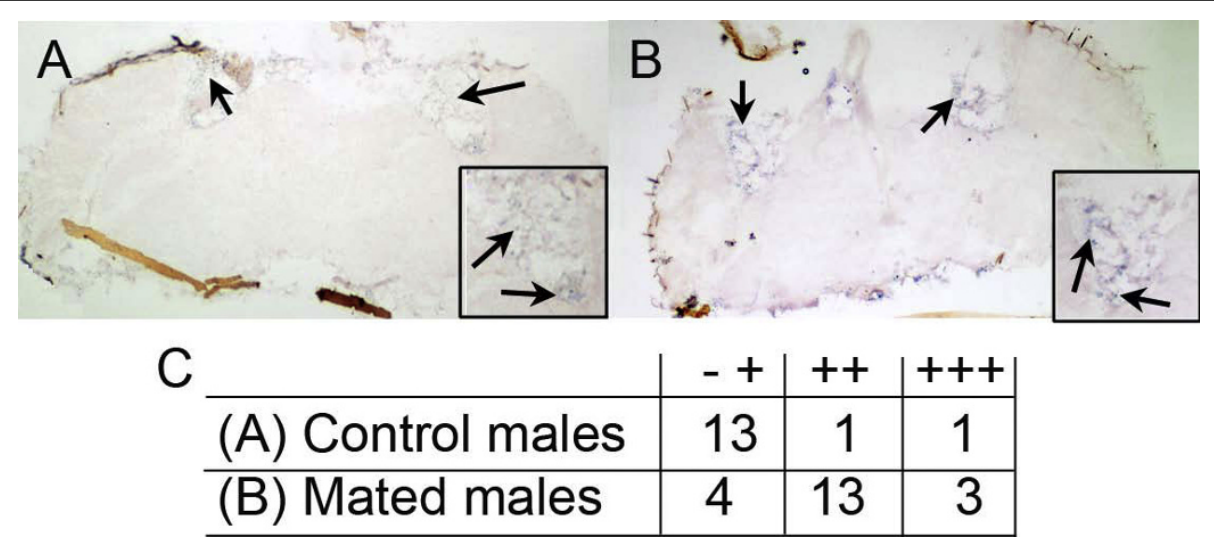

Figure 3 fit expression in the fat body is increased after courtship culminating in mating. In situ hybridization was performed on cryosectioned male heads and confirmed that fit transcript levels were up regulated in adipose tissue (arrows) of mated males (panel B) compared to control males (panel A) as indicted by increased intensity of purple staining in mated male fat body. Insets in panels A and B show magnified views of head fat. Qualitative assessment of signal intensity in both treatment groups indicates that fit expression increased in mated male heads (panel C).

be reflected in altered transcriptional profiles. Of the 47 genes with altered expression 2 hrs after mating (Tables 1 and 2), only 1 gene, fit, is also up regulated in males after 5 min of courtship [12]. CG16772 is up regulated 2 hrs after mating but is down regulated during $5 \mathrm{~min}$ of courtship [12]. CG16772 is one of several fat bodyexpressed immune response genes down regulated during courtship, possibly to allow energetic resources to be directed toward offspring production rather than immunity [12,22]. After mating, expression of CG16772 may increase because contact with a female increases the likelihood of encountering a pathogen.

The fact that few genes overlap between these data sets is not surprising since we assayed different time points ( $5 \mathrm{~min}$ or $2 \mathrm{hrs}$ ), different tissues (whole bodies in previous studies versus heads in this study) and different behaviors (courtship alone versus courtship culminating in mating). We also used different approaches

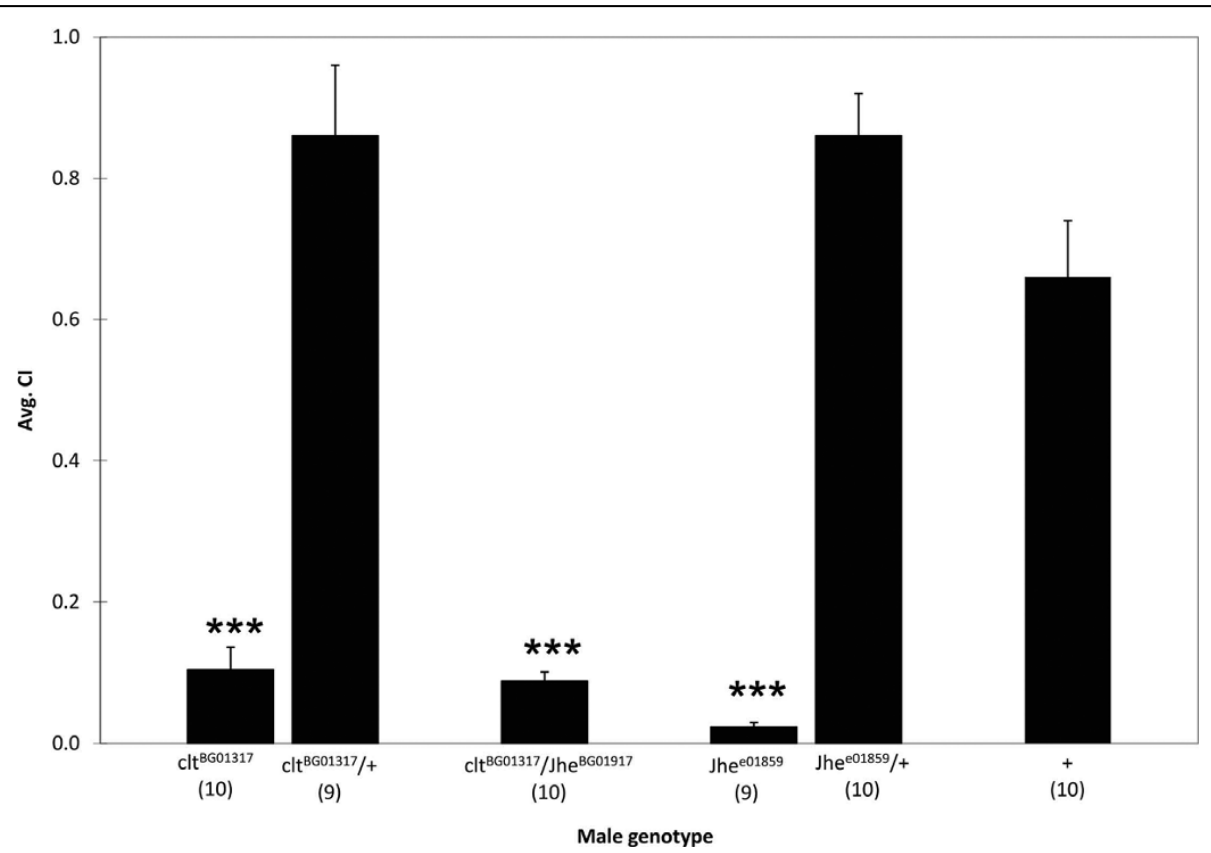

Figure $4 \mathrm{Jhe}$ and clt mutants reduce courtship toward females. Mutant males homozygous for P-element insertions in Jhe or clt showed reduced courtship $\left({ }^{* *} p<0.001\right)$ under red light compared to sibling heterozygous and wild-type controls. Jhe $e^{e 01859}+/+c 1 t^{B G 01317}$ mutant males showed significant reductions in courtship compared to either heterozygote or the wild-type control. $(\mathrm{N})$ reflects sample size. Error bars are SEM. 


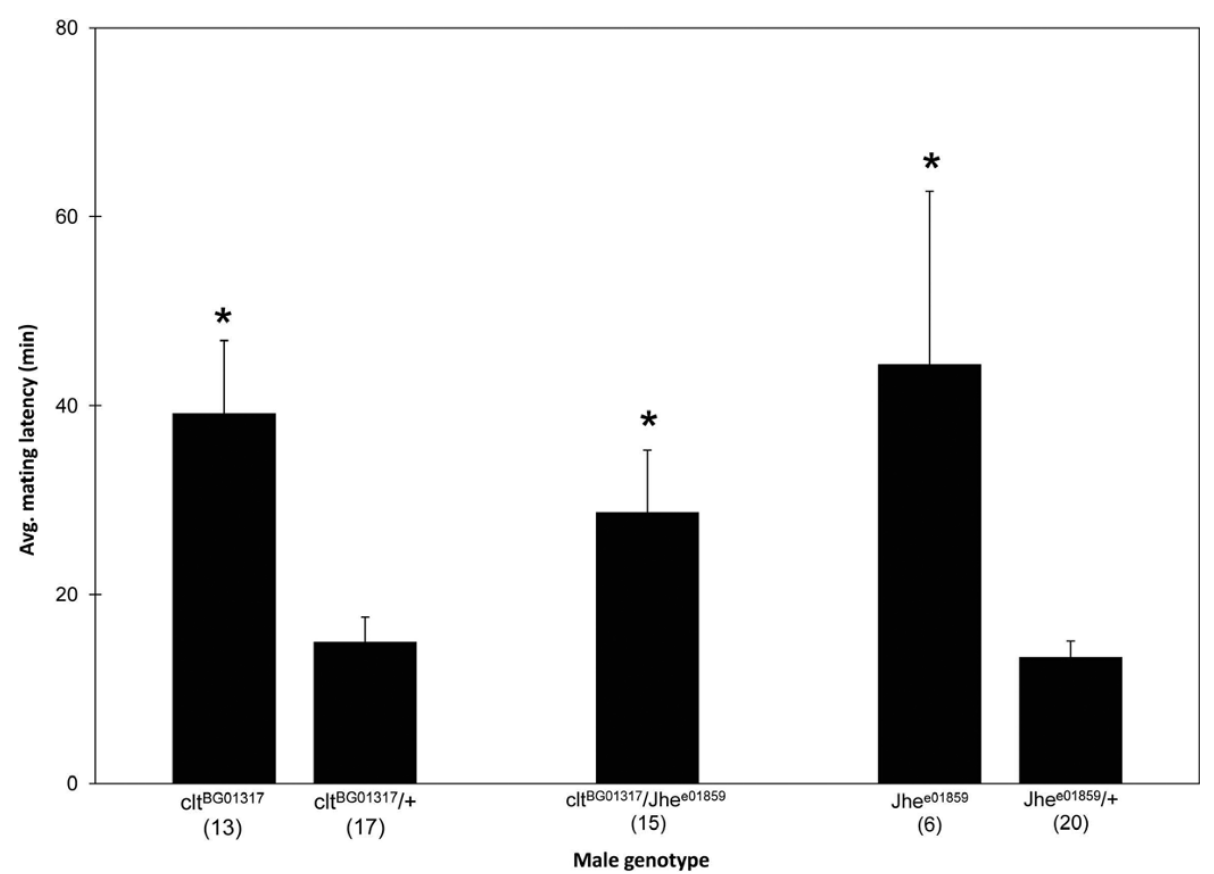

Figure 5 Mating latency is increased in Jhe and clt mutants. Under red light conditions, homozygous and transheterozygous mutant males had significantly (ANOVA $p<0.01$, Tukey's ${ }^{*} p<0.05$ ) increased mating latencies toward CS virgin females regardless of the mating bout $\left(1^{\text {st }}\right.$, $2^{\text {nd }}$, or $3^{\text {rd }}$; therefore, overall average mating latencies are shown. $(\mathrm{N})$ reflects sample size. Error bars are SEM.

for analyzing the data due to the differences in experimental design for each test. The analysis strategies provide us a conservative estimate of the transcripts affected by courtship and mating.

We predict that some mating-responsive genes facilitate an increased male mating efficiency for future encounters. Little is known about how repeated matings affect male mating latency, duration or fecundity. After his first mating, the male may perceive and process female stimuli more rapidly, may be more appealing to the female, or may be physiologically primed for subsequent matings by replenishment of Acps, sperm or other seminal proteins, resulting in decreased courtship or mating latencies. Alterations in gene expression, such as those described here and in our earlier work [12,22], may contribute to these expected behavioral and physiological changes.

\section{Gene expression in adipose tissue}

The fat body is a secretory tissue [reviewed in [59]] whose effects on fly reproductive behavior have previously been described [[37,39,40,43]; reviewed in [52]]. The majority of mating-responsive genes are expressed in adult adipose tissue (fat body) (Table 4), and we analyzed a subset of six up-regulated genes to show that they are expressed in adipose tissue surrounding the brain (Figs. 2 and 3). Furthermore, we observed increased expression of fit in male adipose tissue after courtship followed by mating (Fig. 3). fit also is expressed in the head fat of females and originally was named based upon its high expression in females under the control of Sex-lethal [39], which is the initial regulatory gene in the somatic sex-determination hierarchy.

Other studies also indicated that several matingresponsive genes identified in our study are expressed in the fat body surrounding the brain. Larval serum protein $2(L s p 2)$ is expressed in the head fat of both sexes [60]. Of the 25 genes up regulated by courtship and mating, 14 are detectable (signal strength greater than 20) in brain and 21 genes are detectable in fat body based upon a microarray analysis of adult mRNA expression levels [53]. Of these 25 up regulated genes, 16 are enriched in the fat body relative to other adult tissues (Table 4).

Taken together, these results imply that the brain is not the only tissue responding to or regulating postmating behavior, but that adipose tissue plays a role in this process as well. In response to mating, a signaling cascade initiated by neurosecretory cells may transmit the signal to the surrounding fat body. The fat body then could perpetuate the signal by secreting factors that influence neuronal or non-neuronal tissues. We hypothesize that expression level changes in the brain alter neuronal signaling either directly or indirectly, which impacts the processing of sensory cues and targets other reproductively important tissues. 


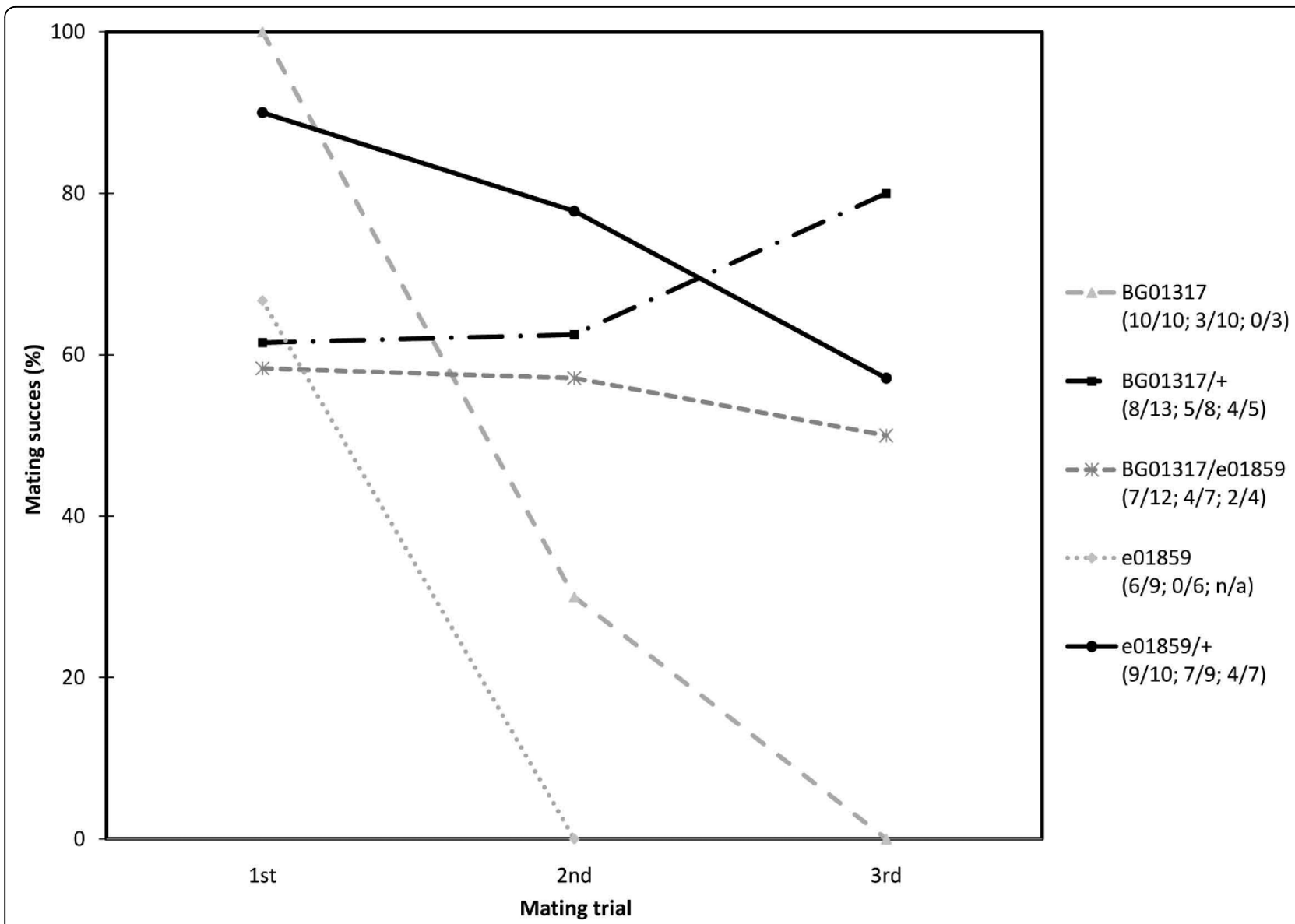

Figure 6 Mating success decreases in Jhe and clt mutants. Jhe/t and clt/+ control males successfully mated with 3 females in succession, while experimental Jhe and clt mutant males significantly (Binary Logistic Regression, genotype $p<0.01$, trial $p<0.0001$, interaction $p<0.0001$ ) decreased their mating success with the $2^{\text {nd }}$ and $3^{\text {rd }}$ females. No. of successful matings/Total no. of pairings for $1^{\text {st }} ; 2^{\text {nd }} ; 3^{\text {rd }}$ trials are shown.

\section{Juvenile hormone esterases and male reproductive behavior}

Another mating-responsive gene, Jhe, is also expressed in adipose tissue [61-64] and functions in reproductive behavior (Figs. 4, 5, 6). Jhe and three closely related esterase genes (clt, Jhedup, and CG7529) have juvenile hormone esterase (JHE) activity in vitro. JHEs together with juvenile hormone epoxide hydrolases hydrolyze Juvenile hormone $(\mathrm{JH})$ to regulate $\mathrm{JH}$ levels $[65,66]$. Since the expression is positively regulated by JH [67], the mating-induced increase in Jhe expression identified in our study may be $\mathrm{JH}$ dependent.

Much of our understanding of physiological functions of $\mathrm{JH}$ comes from studies investigating its function during development [reviewed in [68]]. However, JH also has important post-developmental functions such as promoting accessory gland protein (Acp) synthesis [69]. During mating Acps are transferred, along with sperm, to the female [70], and the transfer of Acps triggers male synthesis of new Acps [58]. Males also transfer Sex-peptide to the female during mating [71-73]. Sex-peptide increases $\mathrm{JH}$ levels in females [74], which stimulates egg development [75]. However, possible mating-induced changes in male JH levels have not been evaluated. Since ejaculate components must be replenished after mating, we hypothesize that male $\mathrm{JH}$ levels increase after mating to stimulate Acp synthesis. The increase in $\mathrm{JH}$ would up regulate the expression which would, in turn, reduce $\mathrm{JH}$ levels once the ejaculate components have been replenished.

$\mathrm{JH}$ also has a role in modulating behavior since males with reduced $\mathrm{JH}$ court females less intensely [76], Our data suggest that an increase in $\mathrm{JH}$, caused by reduction of Jhe or clt, may also disrupt courtship (Figs. 4, 5, 6). Jhe and clt deficient males, which likely have increased levels of $\mathrm{JH}$, court less vigorously (Fig. 4), have increased mating latencies (Fig. 5), and have reduced mating success (Fig. 6). This situation exemplifies the complex regulation governing behavior and implies that $\mathrm{JH}$ levels must be tightly regulated in order to ensure appropriate behavioral and physiological responses. 


\section{Gene expression in the brain}

Although we are particularly interested in the large number of fat-expressed genes that were identified in this and earlier screens [12,22], we also note that several of the identified transcripts are expressed in brains as would be expected for genes that function in behavior. Proper function of the nervous system relies on the appropriate cellular architecture, connections and signaling. Behavior requires the sensory systems to perceive the information accurately and transmit such information to the brain for processing. The brain can then transmit the signal to the appropriate output pathways which can modify signaling in tissues such as the fat body or the brain itself. Therefore the establishment and maintenance of the brain (and sensory systems) is vital to the organism's ability to respond to its environment and experiences. It is possible that mating-responsive genes act in the development or maintenance of a mated male brain as opposed to a naïve male brain.

Thirteen of the 21 fat-expressed genes up regulated in mated males are also expressed in brains at detectable levels [53]; a single transcript, CG4288 is detected in brains but not fat [53]. None of these genes have known function in behavior, but their reported mutant phenotypes or molecular functions indicate that several of the loci may have important neural maintenance functions.

For example, mutants for bgm, an enzyme involved in fatty acid metabolism that is expressed in both the brain and fat, have a neurodegeneration phenotype in response to accumulation of long chain fatty acids [77]. Another gene that potentially functions in a neurodegeneration pathway is Phosphatidyl-serine synthase, which responds to changes in polygluatmate (polyQ) levels [78]. polyQ diseases, including Huntington's Disease, are adult on-set progressive neural degeneration diseases caused by the accumulation of glutamate repeats [79].

Cellular homeostasis is important in the maintenance and function of the Drosophila brain. One gene that helps maintain this homeostasis is Iron regulatory protein $1 B(\operatorname{Irp}-1 B)$ which encodes a protein that binds to iron-responsive elements (IREs) to regulate iron metabolism [80]. In addition to affecting cell survival and homeostasis, neural morphology might also be regulated by mating-responsive candidates. Mutants of Pabp2 show pathfinding and targeting defects in the larval neuromuscular junction [81].

\section{Mating-responsive genes and the sex-determination hierarchy}

This genome-wide analysis identified known sexdetermination hierarchy target genes such as fit. Three other mating-responsive genes (CG16772, Prx2540-2, and CG16898) (Tables 1 and 2) are also regulated by the sex-determination hierarchy [41]. Transcriptional profiling of mutants for a variety of sex-determination hierarchy genes indicates that Prx2540-2 and CG16898 are regulated by fruitless (fru), while fit is downstream of transformer (tra). CG16772 may also function downstream of tra [41].

The splicing factor squid (sqd) is up regulated in mated male heads (Table 1). Interestingly, primary transcripts of the sqd locus are sex-specifically spliced in the head as well as the germline, although it is not known if $s q d$ splicing is regulated by the sex-determination hierarchy [82]. It is possible that sqd and other matingresponsive loci function as downstream targets of the sex-determination hierarchy to regulate morphological and behavioral differences between male and female Drosophila. Alternatively, there may be other pathways (such as those that regulate alternative splicing) that function together with the sex-determination hierarchy to regulate reproductive behavior.

We predict that mating-responsive genes also function in other aspects of reproduction and behavior; therefore, we propose this genome-wide approach as a powerful tool for determining the genetic pathways and intracellular processes regulating reproduction, both at the behavioral and physiological levels.

\section{Methods}

\section{Microarray Analysis}

The wild-type Canton-S (CS) strain was isogenized to reduce genetic variation and the isoline was kept at $25^{\circ} \mathrm{C}$ on a 12-hr light/dark cycle. Twenty or fewer virgin CS males were aged collectively for 3 days at $25^{\circ} \mathrm{C}$. On day 4 , individual males were aspirated into vials. Virgin females were collected and aged in groups of 20 or fewer flies for 4 days at $25^{\circ} \mathrm{C}$.

On day 5 , males were equally divided into two treatment groups. One group (referred to as "mated males") consisted of individual males that were placed with a female for courtship and mating, while the second group of males (referred to as "control males") was mock exposed to a female. We tested both groups at the same time to allow for paired microarray and Cyber- $\mathrm{T}$ analyses (see below). For the mated male group, a single, aged virgin female was aspirated into each male's vial. The control males were treated identically except that no female was transmitted during the aspiration process.

Upon completion of mating, females were removed from the vials. Males from both treatment groups were quick frozen $2 \mathrm{hrs}$ later and stored at $-80^{\circ} \mathrm{C}$ for future RNA extraction; only pairs for which the mated male had a mating latency less than $30 \mathrm{~min}$ and mating duration of 18-30 min were collected for RNA extraction. Seventy-four percent of mated males tested met this 
requirement. All procedures were conducted at the same time each day to control for circadian effects.

Head tissue was separated from the remaining body by vortexing quick-frozen flies. Male heads were assigned to one of 20 groups (30 heads in each group; 10 mated and 10 control RNA preparations) so that control and mated samples collected together could be analyzed by paired statistical comparisons. Following standard protocols, total RNA from head tissue was extracted in Trizol (Invitrogen, Carlsbad, CA, USA). Total head RNA preparations from 10 groups ( 5 control groups and their corresponding mated groups) were sent to the University of Kentucky MicroArray Core Facility for labeling and hybridization to Affymetrix Drosophila 2.0 Genome Arrays following standard Affymetrix (Santa Clara, CA, USA) protocols.

Expression values were generated similarly to previous experiments [12,22] using five algorithms (PM, PMMM, MAS 5.0, GCRMA, and GeneSpring). Multiple expression value algorithms were used to control for variation among the algorithms and to generate a statistically stronger candidate gene set. We used dChip's PM (perfect match between the probe and target sequence) and PM-MM (one nucleotide between the probe and target sequence is mismatched) algorithms [83], as well as those implemented by GCOS (MAS 5.0, Affymetrix), R (GCRMA) [84], and GeneSpring (Agilent, Santa Clara, CA, USA). For the dChip algorithms, expression values were only considered if greater than 50 ; for the other 3 methods, expression values were required to be greater than 100. To test for significance, we used Cyber-T's Bayesian $t$-test analysis [85]. Candidate matingresponsive genes included those whose expression differed significantly $(\mathrm{p}<0.001)$ between control male heads and mated male heads in at least 3 expression value data sets and had a false discovery rate less than 0.05 [86]. With such stringent criteria, we did not specify a particular fold change cut-off value.

\section{qPCR}

To confirm the microarray results, qPCR was performed on 10 independent samples (5 mated and 5 control RNA preparations) that were collected as described above but were not used in the microarray analysis. polyA $^{+}$RNA was isolated from each of the 10 samples using the Oligotex mRNA mini kit (Qiagen, Netherlands). cDNA was synthesized using the SuperScript First-Strand Synthesis System (Invitrogen, Carlsbad, CA, USA). We designed primers to amplify 10 up-regulated and 3 down-regulated genes, choosing genes that are predicted to be enriched in brain, fat body or both tissues based upon FlyAtlas expression data [53]. When possible, primer pairs were designed across introns to control for amplification specificity. Genes that are expressed at low levels in the head [[53]; L. L. Ellis and G. E. Carney, unpublished results] were not tested.

Using the SYBR Green PCR Mastermix (Applied Biosystems, Foster City, CA, USA), $2 \mu \mathrm{L}$ of a 1:4 dilution of each template was run in triplicate in the ABI7500 (Applied Biosystems, Foster City, CA, USA) using default parameters. Control reactions lacking template and controls with template but without Reverse Transcriptase were used. Primer-specific amplification was determined by analyzing dissociation curves for each primer pair.

mRNA levels were determined by the Relative Standard Curve Method (Applied Biosystems, Foster City, CA, USA), and candidate gene transcript levels were normalized to rp 49 transcript levels. Normalizing the mated male transcript levels to the control male transcript levels generated a relative fold change. We also analyzed trends in the average relative transcript levels of each treatment (control and mated) using the twotailed $t$-test. Secondary qPCR analysis confirmed increased expression of CG6188 and decreased expression of alpha Esterase-2.

Regression of mean expression microarray analysis fold changes compared to independent qPCR fold changes indicated a highly significant positive correlation between results obtained by the two methods $(r=$ $0.51, \mathrm{~N}=10, \mathrm{p}=0.021$ ).

\section{In situ hybridization}

Digoxigenin (DIG)-labeled sense and antisense RNA probes were made from cDNA clones for six candidate genes with predicted fat body expression following the manufacturer's standard protocol (Roche, Nutley, NJ, USA). The genes and their corresponding cDNA clones were CG4825 (LD10327), CG8449 (GH10459), CG13360 (LP09811), bubblegum (bgm) (GM14009), fit (RH40291) and Prx2540-2 (RH69586). Expression of fit is regulated by $t r a$ while expression of Prx2540-2 is regulated by fruitless (fru) [41]; tra and fru are regulatory components of the sex-determination hierarchy. Antisense and sense probes were hydrolyzed into $200 \mathrm{bp}$ fragments and in situ hybridization to male brains, head carcass and abdominal cuticle was performed as described in [33]. Antisense probes detected expressed transcripts in each case, while sense probes served as negative controls for expression.

To verify the increased expression of fit in male head tissue after courtship followed by mating, virgin $C S$ males were collected $2 \mathrm{hrs}$ after mating and compared to virgin $C S$ control males that did not mate with a female. After treatment, males were cryosectioned in OCT compound and in situ hybridization was performed on the sections as described previously [37]. Control and mated tissues were placed on the same 
slide to control for histochemical reaction time. We qualitatively assessed fit expression in adipose tissue lining the brain from non-existent (-) to highly expressed $(+++)$.

\section{Courtship assays}

All flies were kept on a 12 -hr light/dark cycle at $25^{\circ} \mathrm{C}$. P-element insertion mutations in Jhe and cricklet (clt) were obtained from the Bloomington Drosophila Stock Center $\left(c l t^{B G 01317}\right)$ and the Exelixis Collection at Harvard Medical School $\left(J h e^{e 01859}\right)$. These insertions are likely hypomorphs since they are located in proximal promoter regions. Each P-element was backcrossed into the $C S$ background to generate a genetically similar control that had one wild-type copy of Jhe or clt. To test for a genetic interaction between Jhe and $c l t$, the two insertion strains, Jhe $e^{e 01859}$ and $\mathrm{clt}^{B G 01317}$, were crossed to generate transheterozygous flies containing a single Pelement insertion in each gene $\left(J h e^{e 01859}+/+c l t^{B G 01317}\right)$. Virgin P-insertion or control males were collected and stored individually for 4 to 5 days; virgin $C S$ females were aged collectively for 3 to 5 days.

Behavioral assays were conducted at $22^{\circ} \mathrm{C}$ under red light conditions to diminish the effect of eye color on vision and courtship. We video recorded the interactions with a digital camcorder so that subsequent analyses could be performed. To analyze courtship behavior, a male was aspirated into a mating chamber (diameter = $1 \mathrm{~cm}$ ) and a virgin $C S$ female was introduced $2 \mathrm{~min}$ later. The pair was video recorded for $10 \mathrm{~min}$. The courtship index (CI; percentage of time the male spent performing courtship during the initial $10 \mathrm{~min}$ of observation) and courtship latency (time until courtship occurs) were calculated. CI values were arcsine transformed for statistical analysis. Two-tailed $t$-test comparisons between homozygous mutants and controls were calculated to determine significance $(\mathrm{p}<0.05)$. Jhe $e^{e 01859}$ $+/+c^{B G 01317}$ males were compared to both control genotypes (two-tailed $t$-test).

\section{Fertility Assays}

The ability of a male to mate with multiple $C S$ females and the fecundity of these matings was also assessed. Jhe and clt mutants and heterozygous controls, as well as $C S$ virgin females, were collected and aged as described for the courtship assay. Under red light, a male was aspirated into a mating chamber, followed by a $C S$ virgin female. The male was given 2 hrs to mate with the female. If mating occurred, the female was placed in a vial with food to measure fecundity (number of eggs laid and number of adult offspring) and the male was placed in a new mating chamber. A second $C S$ virgin female was aspirated into the new chamber and the pair was given 2 hrs to mate. If the second mating occurred, the female was placed in a vial for later progeny counts, and the male was moved to another chamber for mating with a third and final female. The third mated female was also kept for further analysis. For the first mating bout, all $10 \mathrm{clt}{ }^{B G 01317}$ males mated, while only three of the ten males mated with the second female and none of the 3 males mated with the third female. Eight out of $13 \mathrm{clt}^{\text {BGO1317/ }}+$ males mated with the first female, five of those eight males mated with the second female and four of the remaining five males mated with the third female. Jhe $e^{e 01859}$ males only mated with the first female (six out of nine males). However, nine of ten $J h e^{e 01859} /+$ males mated with the first female, seven of those nine males mated with the second female and four of the seven males mated with the third female. For the transheterozygous $\mathrm{clt}^{B G 01317} / J_{h} e^{e 01859}$ males, seven of 12 mated with the first female, four of seven males mated with the second female and two of the four males mated with the third female.

The mating latencies and durations for each of the three possible matings were measured and significance was determined by Univariate ANOVA analysis using genotype and mating trial as fixed variables with Tukey's posthoc analysis (SPSS). Males that did not mate within the 2 $\mathrm{hr}$ window were scored as being unsuccessful. Using linear regression, we assessed the significance $(\mathrm{p}<0.05)$ of genotype and mating bout on mating success.

For 6 days following the assay, the female was transferred to a new vial and the number of eggs laid in each vial was determined. Vials were maintained at $25^{\circ}$ C for 18 days to allow for a count of the total number of adult progeny. Significant effects of genotype and trial on mating latency or duration were measured by the Univariate ANOVA and Tukey's post-hoc analysis. We also measured the significance of genotype, mating bout and day of egg laying on the male's fecundity (Univariate ANOVA and Tukey's post-hoc analysis). Fecundity was measured by the total number of eggs laid and by the arcsine transformed ratio of adult offspring to eggs laid.

\section{Acknowledgements}

We thank Ms. Donna Wall and Dr. Kuey-Chu Chen at the University of Kentucky MicroArray Core Facility for microarray processing. Mr. Bruce Ellis created the electrical probes used for ablations, and Dr. Adam G. Jones provided helpful discussions regarding the statistical analyses. We also thank two anonymous reviewers for their helpful comments on the manuscript. Texas A\&M University provided funding to G.E.C. The microarray data from this study are available through the GEO database, accession number GSE24156.

\section{Author details}

${ }^{1}$ Department of Biology, Texas A\&M University, College Station, TX USA 77843-3258. 2Current Address: Department of Entomology, Texas A\&M University, College Station, TX USA 77843-2475. 


\section{Authors' contributions}

LLE designed and executed experiments, analyzed the data, and helped write the manuscript. GEC conceived and designed experiments and helped write the manuscript. All authors read and approved the final draft.

Received: 20 May 2010 Accepted: 11 October 2010

Published: 11 October 2010

\section{References}

1. Dukas R, Mooers AO: Environmental enrichment improves mating success in fruit flies. Anim Behav 2003, 66:741-749.

2. Gailey DA, Hall JC, Siegel RW: Reduced reproductive success for a conditioning mutant in experimental populations of Drosophila melanogaster. Genetics 1985, 111:795-804.

3. Siegel RW, Hall JC: Conditioned responses in courtship behavior of normal and mutant Drosophila. Proc Natl Acad Sci USA 1979, 76:3430-3434.

4. Ueda A, Kidokoro Y: Aggressive behaviors of female Drosophila melanogaster are influenced by their social experience and food resources. Physiol Entomol 2002, 27:21-28.

5. Yurkovic A, Wang O, Basu AC, Kravitz EA: Learning and memory associated with aggression in Drosophila melanogaster. Proc Natl Acad SCl USA 2006, 103:17519-17524.

6. Kozorovitskiy Y, Hughes M, Lee K, Gould E: Fatherhood affects dendritic spines and vasopressin V1a receptors in the primate prefrontal cortex. Nat Neurosci 2006, 9:1094-1095

7. Mori T, Hiraka I, Kurata Y, Kawachi H, Kishida O, Nishimura K: Genetic basis of phenotypic plasticity for predator-induced morphological defenses in anuran tadpole, Rana pirica, using CDNA subtraction and microarray analysis. Biochem Biophys Res Commun 2005, 330:1138-1145.

8. Stewart BA, McLean JR: Population density regulates Drosophila synaptic morphology in a Fasciclin-II-dependent manner. J Neurobiol 2004, 61:392-399.

9. Technau GM: Fiber number in the mushroom bodies of adult Drosophila melanogaster depends on age, sex, and experience. J Neurogenet 2007, 21:183-196.

10. Anseloni VCZ, He F, Novikova SI, Robbins MT, Lidow IA, Ennis M, Lidow MS: Alterations in stress-associated behaviors and neurochemical markers in adult rats after neonatal short-lasting local inflammatory insult Neuroscience 2005, 131:635-645

11. Burmeister SS, Jarvis ED, Fernald RD: Rapid behavioral and genomic responses to social opportunity. PLoS Biol 2005, 3:1996-2004.

12. Carney GE: A rapid genome-wide response to Drosophila melanogaster social interactions. BMC Genomics 2007, 8:288.

13. Levine JD, Funes $P$, Dowse HB, Hall JC: Resetting the circadian clock by social experience in Drosophila melanogaster. Science 2002. 298:2010-2012.

14. Mehren JE, Griffith LC: Calcium-independent calcium/calmodulindependent protein kinase II in the adult Drosophila CNS enhances the training of pheromonal cues. J Neurosci 2004, 24:10584-10593.

15. Murata S, Yoshiara T, Lim CR, Sugino M, Kogure M, Ohnuki T, Komurasaki T, Matsubara K: Psychophysiological stress-regulated gene expression in mice. FEBS Lett 2005, 579:2137-2142.

16. Reiser M, Poeggel G, Schnabel R, Schroder H, Braun K: Effect of social experience on dopamine-stimulated adenylyl cyclase activity and $\mathrm{G}$ protein composition in chick forebrain. J Neurochem 1999, 73:1293-1299.

17. Shen CP, Tsimberg Y, Salvadore C, Meller E: Activation of Erk and JNK MAPK pathways by acute swim stress in rat brain regions. BMC Neurosci 2004, 5:36.

18. Greenspan RJ: Understanding the genetic construction of behavior. Sci Am 1995, 272:72-78.

19. Greenspan RJ, Ferveur J-F: Courtship in Drosophila. Annu Rev Genet 2000, 34:205-232.

20. Billeter J-C, Goodwin SF, O'Dell KM: Genes mediating sex-specific behaviors in Drosophila. Adv Genet 2002, 47:87-116.

21. Tompkins L: Genetic analysis of sex appeal in Drosophila. Behav Genet 1984, 14:411-440.

22. Ellis LL, Carney GE: Drosophila melanogaster males respond differently at the behavioral and genome-wide levels to Drosophila melanogaster and Drosophila simulans females. J Evol Biol 2009, 22:2183-2191.
23. Siwicki KK, Ladewski L: Associative learning and memory in Drosophila: beyond olfactory conditioning. Behav Processes 2003, 64:225-238.

24. Ewing AW: Functional-aspects of Drosophila courtship. Biol Rev 1983, 58:275-292.

25. Mehren JE, Ejima A, Griffith LC: Unconventional sex: Fresh approaches to courtship learning. Curr Opin Neurobiol 2004, 14:745-750.

26. Cline TW: Reflections on a path to sexual commitment. Genetics 2005, 169:1179-1185.

27. Shirangi TR, McKeown M: Sex in flies: What 'body-mind' dichotomy? Dev Biol 2007, 306:10-19.

28. Demir E, Dickson BJ: fruitless splicing specifies male courtship behavior in Drosophila. Cell 2005, 121:785-794.

29. Finley KD, Taylor BJ, Milstein M, McKeown M: dissatisfaction, a gene involved in sex-specific behavior and neural development of Drosophila melanogaster. Proc Natl Acad Sci USA 1997, 94:913-918.

30. Kimura K, Ote M, Tazawa T, Yamamoto D: Fruitless specifies sexually dimorphic neural circuitry in the Drosophila brain. Nature 2005, 438:229-233.

31. Manoli DS, Foss M, Villella A, Taylor BJ, Hall JC, Baker BS: Male-specific fruitless specifies the neural substrates of Drosophila courtship behavior. Nature 2005, 436:395-400.

32. Stockinger $P$, Kvitsiani $D$, Rotkopf $S$, Tirian L, Dickson BJ: Neural circuitry that governs Drosophila male courtship behavior. Cell 2005, 121:795-807.

33. Arbeitman MN, Fleming AA, Siegal ML, Null BH, Baker BS: A genomic analysis of Drosophila somatic sexual differentation and its regulation. Development 2004, 131:2007-2021.

34. Burtis KC, Coschigano KT, Baker BS, Wensink PC: The Doublesex proteins of Drosophila melanogaster bind directly to a sex-specific yolk protein gene enhancer. EMBO J 1991, 10:2577-2582.

35. Cann MJ, Chung E, Levin LR: A new family of adenylyl cyclase genes in the male germline of Drosophila melanogaster. Dev Genes Evol 2000, 210:200-206.

36. Dalton JE, Lebo MS, Sanders LE, Sun F, Arbeitman MN: Ecdysone receptor acts in fruitless- expressing neurons to mediate Drosophila courtship behaviors. Curr Biol 2009, 19:1447-1452.

37. Dauwalder B, Tsujimoto S, Moss J, Mattox W: The Drosophila takeout gene is regulated by the somatic sex-determination pathway and affects male courtship behavior. Genes Dev 2002, 16:2879-2892.

38. Drapeau MD, Radovic A, Wittkopp PJ, Long AD: A gene necessary for normal male courtship, yellow, acts downstream of fruitless in the Drosophila melanogaster larval brain. J Neurobiol 2003, 55:53-72.

39. Fujii S, Amrein H: Genes expressed in the Drosophila head reveal a role for fat cells in sex-specific physiology. EMBO J 2002, 21:5353-5363.

40. Fujii S, Toyama A, Amrein H: A male-specific fatty acid omegahydroxylase, SXE1, is necessary for efficient male mating in Drosophila melanogaster. Genetics 2008, 180:179-90.

41. Goldman TD, Arbeitman MN: Genomic and functional studies of Drosophila sex hierarchy regulated gene expression in adult head and nervous system tissues. PLoS Genet 2007, 3:e216.

42. Kopp A, Duncan I, Godt D, Carroll SB: Genetic control and evolution of sexually dimorphic characters in Drosophila. Nature 2000, 408:553-559.

43. Lazareva AA, Roman G, Mattox W, Hardin PE, Dauwalder B: A role for the adult fat body in Drosophila male courtship behavior. PLoS Genet 2007, 3 e16.

44. Dukas R: Experience improves courtship in male fruit flies. Anim Behav 2005, 69:1203-1209.

45. Polejack A, Tidon R: Learning of courtship components in Drosophila mercatorum (Paterson \& Wheller) (Diptera, Drosophilidae). Rev Bras Entomol 2007, 51:82-86.

46. Anholt RRH, Dilda CL, Chang S, Fanara JJ, Kulkarni NH, Ganguly I, Rollmann SM, Kamdar KP, Mackay TFC: The genetic architecture of odorguided behavior in Drosophila: Epistasis and the transcriptome. Nat Genet 2003, 35:180-184.

47. Ceriani MF, Hogenesch JB, Yanovsky M, Panda S, Straume M, Kay SA: Genome-wide expression analysis in Drosophila reveals genes controlling circadian behavior. J Neurosci 2002, 22:9305-9319.

48. Dubnau J, Chiang AS, Grady L, Barditch J, Gossweiler S, McNeil J, Smith P, Buldoc F, Scott R, Certa U, Broger C, Tully T: The staufen/pumilio pathway is involved in Drosophila long-term memory. Curr Biol 2003, 13:286-296. 
49. Lawniczak MK, Begun DJ: A genome-wide analysis of courting and mating responses in Drosophila melanogaster females. Genome 2004, 47:900-910.

50. Mackay TFC, Heinsohn SL, Lyman RF, Moehring AJ, Morgan TJ, Rollmann SM: Genetics and genomics of Drosophila mating behavior. Proc Natl Acad Sci USA 2005, 102:6622-6629.

51. Toma DP, White KP, Hirsch J, Greenspan RJ: Identification of genes involved in Drosophila melanogaster geotaxis, a complex behavioral trait. Nat Genet 2002, 31:349-353.

52. Dauwalder B: Systems behavior: Of male courtship, the nervous system and beyond in Drosophila. Curr Genomics 2008, 9:517-524.

53. Chintapalli VR, Wang J, Dow JA: Using FlyAtlas to identify better Drosophila melanogaster models of human disease. Nat Genet 2007, 39:715-720.

54. Campbell PM, Harcourt RL, Crone EJ, Claudianos C, Hammock BD, Russell RJ, Oakeshott JG: Identification of a juvenile hormone esterase gene by matching its peptide mass fingerprint with a sequence from the Drosophila genome project. Inesct Biochem Mol Biol 2001, 31:513-520.

55. Mack PD, Kapelnikov A, Heifetz Y, Bender M: Mating-responsive genes in reproductive tissues of female Drosophila melanogaster. Proc Natl Acad Sci USA 2006, 103:10358-10363.

56. McGraw LA, Clark AG, Wolfner MF: Post-mating gene expression profiles of female Drosophila melanogaster in response to time and to four male accessory gland proteins. Genetics 2008, 179:1395-1408.

57. McGraw LA, Gibson G, Clark AG, Wolfner MF: Genes regulated by mating, sperm, or seminal proteins in mated female Drosophila melanogaster. Curr Biol 2004, 14:1509-1514.

58. DiBenedetto AJ, Harada HA, Wolfner MF: Structure, cell-specific expression, and mating-induced regulation of a Drosophila melanogaster male accessory gland gene. Dev Biol 1990, 139:134-148.

59. Schlegel A, Stainier DYR: Lessons from "lower" organisms: What worms, flies, and zebrafish can teach us about human energy metabolism. PLoS Genet 2007, 3:2037-2048.

60. Benes $H$, Edmondson RG, Fink P, Keizlarova-Lepesant J, Lepesant JA, Miles JP, Spivey DW: Adult expression of the Drosophila $L s p-2$ gene. Dev Biol 1990, 142:138-146.

61. Anand A, Crone EJ, Zera AJ: Tissue and stage-specific juvenile hormone (JHE) and epoxide hydrolase (JHEH) enzyme activities and Jhe transcript abundance in lines of the cricket Gryllus assimilis artificially selected for plasma JHE activity: Implications for JHE microevolution. J Insect Physiol 2008, 54:1323-1331.

62. Kamimura M, Takahashi M, Kikuchi K, Reza AMS, Kiuchi M: Tissue-specific regulation of Juvenile hormone esterase gene expression by 20 hydroxyecdysone and Juvenile hormone in Bombyx mori. Arch Insect Biochem 2007, 65:143-151.

63. Klages $\mathrm{G}$, Emmerich $\mathrm{H}$ : Juvenile hormone metabolism and juvenile hormone esterase titer in hemolymph and peripheral tissues of Drosophila hydei. J Comp Physiol 1979, 132:319-325.

64. Shanmugavelu S, Baytan AR, Chesnut JD, Bonning BC: A novel protein that binds juvenile hormone esterase in fat body tissue and pericardial cells of the tobacco hornworm Manduca sexta. J Biol Chem 2000, 275:1802-1806.

65. Campbell PM, Healy MJ, Oakeshott JG: Characterization of juvenile hormone esterase in Drosophila melanogaster. Insect Biochem Mol Biol 1992, 22:665-677.

66. Campbell PM, Oakeshott JG, Healy MJ: Purification and kinetic characterization of juvenile hormone esterase from Drosophila melanogaster. Insect Biochem Mol Biol 1998, 28:501-515.

67. Kethidi DR, Xi ZY, Palli SR: Developmental and hormonal regulation of juvenile hormone esterase gene in Drosophila melanogaster. J Insect Physiol 2005, 51:393-400.

68. Flatt T, Tu MP, Tatar M: Hormonal pleiotropy and the juvenile hormone regulation of Drosophila development and life history. Bioessays 2005, 27:999-1010.

69. Wolfner MF, Partridge L, Lewin S, Kalb JM, Chapman T, Herndon LA: Mating and hormonal triggers regulate accessory gland gene expression in male Drosophila. J Insect Physiol 1997, 43:1117-1123.

70. Wolfner MF: Tokens of love: Functions and regulation of Drosophila male accessory gland products. Insect Biochem Mol Biol 1997, 27:179-192.

71. Chen PS: The accessory gland proteins in male Drosophila: Structural, reproductive, and evolutionary aspects. Experientia 1996, 52:503-510.
72. Kubli E: The sex-peptide. Bioessays 1992, 14:779-784.

73. Wolfner MF, Harada HA, Bertram MJ, Stelick TJ, Kraus KW, Kalb JM, Lung YO, Neubaum DM, Park M, Tram U: New genes for male accessory gland proteins in Drosophila melanogaster. Insect Biochem Mol Biol 1997, 27:825-834.

74. Moshitzky P, Fleischmann I, Chaimov N, Saudan P, Klauser S, Kubli E, Applebaum SW: Sex-peptide activates juvenile hormone biosynthesis in the Drosophila melanogaster corpus allatum. Arch Insect Biochem Physiol 1996, 32:363-374.

75. Soller M, Bownes M, Kubli E: Control of oocyte maturation in sexually mature Drosophila females. Dev Biol 1999, 208:337-351.

76. Wilson TG, DeMoor S, Lei J: Juvenile hormone involvement in Drosophila melanogaster male reproduction as suggested by the methoprenetolerant(27) mutant phenotype. Insect Biochem Mol Biol 2003, 33:1167-1175.

77. Min KT, Benzer S: Preventing neurodegeneration in the Drosophila mutant bubblegum. Science 1999, 248:1958.

78. Nelson B, Nishimura S, Kanuka H, Kuranaga E, Inoue M, Hori G, Nakahara H, Miura M: Isolation of gene sets affected specifically by polyglutamine expression: Implication of the TOR signaling pathway in neurodegeneration. Cell Death Diffn 2005, 12:1115-1123.

79. Zoghbi HY, Orr HT: Glutamine repeats and neurodegeneration. Ann Rev Neurosci 2000, 23:217-247.

80. Muckenthaler M, Gunkel N, Frishman D, Cyrklaff A, Tomancak P, Hentze MW: Iron-regulatory protein-1 (IRP-1) is highly conserved in two invertebrate species-characterization of IRP-1 homologues in Drosophila melanogaster and Caenorhabditis elegans. Europ J Biochem 1998, 254:230-237.

81. Liebl FLW, Werner KM, Sheng Q, Karr JE, McCabe BD, Featherstone DE: Genome-wide P-element screen for Drosophila synaptogenesis mutants. J Neurobiol 2006, 66:332-347.

82. Telonis-Scott M, Kopp A, Wayne ML, Nuzhdin SV, McIntyre LM: Sex-specific splicing in Drosophila: Widespread occurrence, tissue specificity and evolutionary conservation. Genetics 2009, 181:421-434.

83. Li C, Wong WH: Model-based analysis of oligonucleotide arrays: Expression index computation and outlier detection. Proc Natl Acad Sci USA 2001, 98:31-36.

84. R Development Core Team: R: A language and environment for statistical computing. R Foundation for Statistical Computing, Vienna 2008.

85. Baldi P, Long AD: A bayesian framework for the analysis of microarray expression data: Regularized $t$-test and statistical inferences of gene changes. Bioinformatics 2001, 17:509-519.

86. Storey JD, Tibshiriani R: Statistical significance for genomewide studies. Proc Natl Acad Sci USA 2003, 100:9440-9445.

doi:10.1186/1471-2164-11-558

Cite this article as: Ellis and Carney: Mating alters gene expression patterns in Drosophila melanogaster male heads. BMC Genomics 2010 11:558.

\section{Submit your next manuscript to BioMed Central and take full advantage of:}

- Convenient online submission

- Thorough peer review

- No space constraints or color figure charges

- Immediate publication on acceptance

- Inclusion in PubMed, CAS, Scopus and Google Scholar

- Research which is freely available for redistribution 